\title{
TWO ADDITIONAL OBSERVATIONS OF EGG LAYING BY PARASITIC BROWN-HEADED COWBIRDS
}

SPENCER G. SEALY and D. GLEN MCMASTER, Department of Zoology, University of Manitoba, Winnipeg, MB R3T 2N2. (Present address of DGM: Saskatchewan Watershed Authority, 101-2022 Cornwall Street, Regina, SK S4P 2K5)

\section{Introduction}

Three of the five species of parasitic cowbirds are known to lay their eggs around sunrise. ${ }^{10-12,17}$ One of these is the Brownheaded Cowbird, which generally lays earlier than its hosts. ${ }^{9,12}$ This act of parasitism by Brown-headed Cowbirds has been witnessed or video-taped, and described

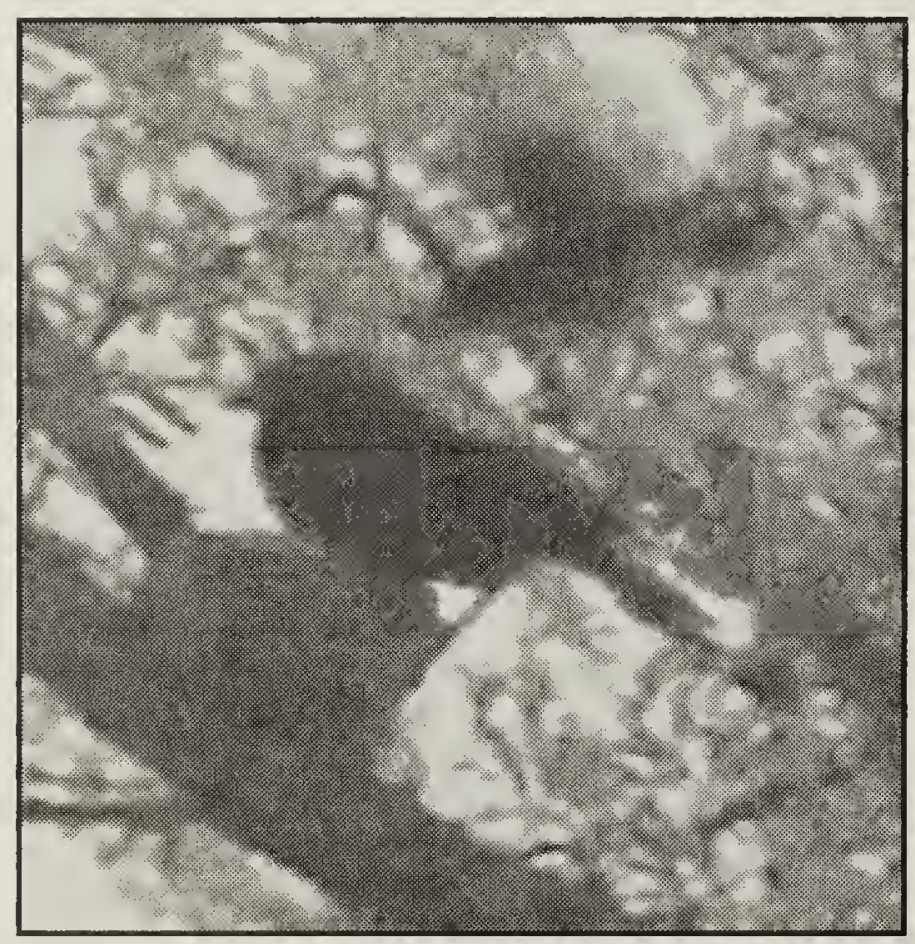

Female Brown-lieaded Cowbird approaching the nest of a Blue-gray Gnatcatcher (with the gnatcatcher attacking the cowbird from above), 25 June 2002, Kinney Co., Texas. The cowbird and at least one gnatcatcher arrived in the vicinity of the nest at 05:30 CST, by 5:32:31 the cowbird was approaching the nest, and laid her egg precisely at 05:33:31, 11 minutes prior to sunrise.

Kevin Ellison in the literature about 50 times, from widespread localities within the species' range: Manitoba, Missouri, Montana, North Dakota, and the Great Lakes region.1,4,10,12,15,16 Eleven of these observations were at Delta Marsh, Manitoba, at four nests of the Yellow Warbler, four of the Red-winged Blackbird, two of the Baltimore Oriole, and at one nest of the Clay-colored Sparrow. ${ }^{10,12}$ Here we present details of two additional acts of parasitism by Brown-headed Cowbirds at Delta Marsh: an additional record for a Yellow Warbler nest and the first description of the timing of parasitism on a Brewer's Blackbird nest.

\section{Observations}

The parasitism events described here were observed during watches of potential host nests in 1993 and 1994, the last two years of watches that began in 1989. The Brewer's Blackbird nest was at the edge of a pasture along the southern edge of Delta Marsh near an oak woodlot; SGS witnessed the parasitism on this nest in 1993. In 1994, DGM observed the parasitism on the Yellow Warbler nest located in riparian habitat of the forested dune ridge that separates Delta Marsh and Lake Manitoba.

Following protocols described in detail elsewhere, ${ }^{8-10,15}$ we watched nests to determine the time of day of laying by Brown-headed Cowbirds and their potential hosts, as well as host behaviour at their 
nests. Briefly, nests were watched from blinds set up the evening before the watch was to take place, or from other concealed vantage points, from 03:30 hr (all times Central Standard Time) through at least 04:30 hr to cover the period around sunrise and the time in which parasitism by Brownheaded Cowbirds was known to occur. ${ }^{12}$ The contents of each nest was recorded the evening before the watch and again before we entered the blinds in the morning, unless the female was still on the nest after roosting there overnight, in which case the nest was inspected the first time the female left in the morning. Watches extended beyond 04:30 hr, in some cases through the early afternoon, to obtain laying times for some host species. ${ }^{9}$ The Brewer's Blackbird nest was watched until the female blackbird laid her own egg, after the cowbird laid its egg, whereas the Yellow Warbler nest was watched for about one hour after the cowbird's egg had been laid, but the female warbler did not lay that morning.

\section{Yellow Warbler}

Upon arrival at the blind at 03:30 hr on 6 June 1994, DGM noted that the female warbler was not on the empty nest, although a male was singing nearby. None was seen near the nest over the next 30 minutes, including at 04:00 hr when a female cowbird flew to the nest, stepped onto the rim and placed her bill into the nest. She quickly settled into the nest and began a series of rhythmic, full-body contractions as the egg was laid. During each of the 4-5 contractions, the female stretched farther forward, until with the last contraction, she pushed so far that her head was below the nest rim and essentially only her cloaca and tail were within the nest cup. This posture gave the bird the appearance of toppling forward off the nest. At this moment, the cowbird apparently laid the egg, righted her body in the nest and then flew off, all the while silent. The cowbird was on the nest for 21 seconds, arriving at 04:00:20 and leaving at $04: 00: 41$; the egg was laid 25 minutes before official sunrise, calculated following Scott's procedure. ${ }^{12}$ Neither adult warbler was seen until 04:22 hr when the female visited the nest, peered into it for 5 seconds, and then left. Observations ceased at 05:00 hr without the warbler laying its first egg that day. The cowbird egg was removed and replaced with a model egg, but the next day the nest had been depredated.

\section{Brewer's Blackbird}

The female blackbird was not on the nest at 03:25 hr on 21 May 1993 when the watch began. The nest, on the ground, contained the same blackbird egg and cowbird egg recorded the previous evening. No blackbirds were heard or seen until 03:51 $\mathrm{hr}$, when one called about $5 \mathrm{~m}$ from the nest. Over the next 4 minutes, two called from at least $10 \mathrm{~m}$ from the nest and out of sight, before they left the area. At 04:09 hr a female cowbird flew to within $6 \mathrm{~m}$ of the nest and landed on the ground, where it remained motionless and out of sight for more than one minute. Still out of sight, the cowbird walked toward the nest (the movement of blades of grass revealed its progress) when suddenly, it stood erect, its head visible above the grass as it looked around for several seconds. Dropping out of sight again, the female continued toward the nest for a few more seconds, but after standing erect twice more, it entered the nest at 04:12 hr and remained in the nest for 37 seconds, during which time it laid its egg (the laying bout). After laying, the cowbird walked about $10 \mathrm{~cm}$ from the nest and flew away, without ever vocalizing. The egg was laid 27 minutes before official sunrise.

At 04:11 hr while the cowbird moved toward the nest, five Brewer's Blackbirds landed about $5 \mathrm{~m}$ from the nest and at least one blackbird uttered an alarm call, the Chow call. ${ }^{7}$ At $04: 31 \mathrm{hr}$ a female blackbird approached the nest for a few seconds and, from then until 04:42 hr, visited the nest twice more before settling on it at $04: 46 \mathrm{hr}$ to begin the laying process. At 05:11 hr, the female left the nest and was immediately joined by a male and they flew off together. 
On the nest for 25 minutes, the female laid about 20 minutes after sunrise. SGS returned to the nest at $03: 25 \mathrm{hr}$ the following morning, but the female flushed from it and the watch was aborted. The nest contained two cowbird eggs and one blackbird egg, one less of the latter than on the previous morning. The missing host egg, undamaged when inspected the previous morning and, hence, not likely removed by the blackbird, ${ }^{5}$ may have been removed by the female cowbird on a return visit to the nest. ${ }^{13}$ On 23 May, the nest contained three blackbird and three cowbird eggs, but by 25 May the contents of the nest had been depredated.

\section{Discussion}

Brown-headed Cowbirds lay their eggs earlier and more quickly than other species of blackbirds and most other songbirds whose laying times and laying bouts have been recorded. $9,12,14$ of the 50 or so observations of acts of parasitism by this species of cowbird, all but two were recorded before or around sunrise. 1,4,10,12,15,16 The latest laying time noted by Scott in a review of laying times of Brown-headed Cowbirds was at least three hours after sunrise, at a Northern Cardinal nest in Indiana. ${ }^{6,12}$ All 11 acts of parasitism published previously for Delta Marsh occurred between 19 and 44 minutes before sunrise $^{10,15}$ and the two observed acts of parasitism reported here, 25 and 27 minutes before sunrise, were within this range. Such consistency of laying time, in the minutes before sunrise before hosts lay, begs the question of whether this behaviour confers an advantage on Brown-headed Cowbirds as brood parasites.

Some authors have argued that by laying around sunrise, Brown-headed Cowbirds are less likely to disturb potential hosts who would be foraging before laying their own eggs and, hence, less attentive at their nests. ${ }^{2,12}$ Our observations, and those of others made in the last 10 years, have confirmed for the Brown-headed Cowbird the narrow window of laying just prior to sunrise. But observations also have shown that females of some potential host species were near thair nests around sunrise, or having roosted in their nests, were in them when cowbirds arrived to lay. Tussles at some nests have ensued between the cowbird and the hosts, but parasitism generally occurred despite the hosts' aggressive behaviour. ${ }^{1,10,15}$ In one study, recognition of the cowbird during laying elicited desertion of parasitized nests by Field Sparrows.' Bronzed Cowbirds and Shiny Cowbirds also lay around sunrise, ${ }^{11,12}$ and laying has been surmised to occur in the parasitic Giant and Screaming cowbirds from sunrise through mid-morning, 12 although direct observations of acts of parasitism are needed to confirm this range of laying times. If these species lay around sunrise, too, this would be strong support for early laying being an adaptation for brood parasitism among the parasitic cowbirds. A consideration of the laying times of parasitic birds elsewhere in the world reveals a wide range of times over the day. ${ }^{3,9}$ This suggests that the time of day of laying depends on the behaviour of particular hosts on and near their nests in relation to constraints on the parasites, such as distance from their roost sites to host nests, foraging and interactions with other individuals.

Rapid laying also was characteristic of parasitism at Delta Marsh, as each cowbird spent between 14 and 119 seconds on nests while laying, ${ }^{10,15}$ with a mean of 45 seconds. The two cowbirds observed here spent 21 and 37 seconds on the nest laying, which were within the range of laying bouts recorded at Delta Marsh. In general, parasitic birds lay rapidly, reducing the chances the parasites will encounter aggressive hosts during laying. ${ }^{14}$ Additional observations and video-tapes of acts of parasitism on many more host species at different latitudes may reveal subtle differences in laying times and also whether some or all hosts occasionally thwart parasitism attempts. 


\section{Acknowledgements}

We thank the staff of the Delta Marsh Field Station (University of Manitoba) for providing logistical support and accommodation during our work at Delta Marsh. Personnel of the Portage Country Club allowed us to watch nests on their property, including the Yellow Warbler nest at which cowbird parasitism was observed and described in this paper. Kevin Ellison provided the video frame of the cowbird in the process of parasitizing the Blue-gray Gnatcatcher's nest, and commented on the manuscript, as did Sharon Gill and Diane Neudorf. Financial support was received from Manitoba Conservation (Wildlife Branch), the Natural Sciences and Engineering Research Council of Canada (grant to SGS, scholarship to DGM) and the University of Manitoba Research Grants Program.

1. BURHANS, D. E. 2000. Morning nest arrivals in cowbird hosts: their role in aggression, cowbird recognition, and host response to parasitism. In: J. N. M. Smith, T. L. Cook, S. I. Rothstein, S. K. Robinson and S. G. Sealy (eds.). Ecology and Management of Cowbirds and their Hosts. University of Texas Press, Austin, Texas. p.161-168.

2. CHANCE, E. P. and H. W. HANN. 1942. The European Cuckoo and the Cowbird. Bird-Banding 13:99-103.

3. DA VIES, N. B. 2000. Cuckoos, Cowbirds and other Cheats. T and A D Poyser, London.

4. GRANFORS, D. A., P. J. PIETZ and L. A. LOYAL. 2001. Frequency of egg and nestling destruction by female Brown-headed Cowbirds at grassland nests. $A u k$ 118:765-769.

5. KEMAL, R. E., and S. I. ROTHSTEIN. 1988. Mechanisms of avian egg recognition: adaptive responses to eggs with broken shells. Animal Behaviour 36:175-183.

6. KINSER, G. W., JR. 1973. Ecology and behavior of the Cardinal, Richmondena cardinalis (L.), in southern
Indiana. Ph.D. thesis, University of Indiana, Bloomington.

7. MARTIN, S. G. 2002. Brewer's Blackbird (Euphagus cyanocephalus). In: Poole, A. and F. Gill (eds.). The Birds of North America, No. 616. The Birds of North America, Inc., Philadelphia, PA.

8. MCMASTER, D. G., S. G. SEALY, S. A. GILL and D. L. NEUDORF. 2000. Timing of egg laying in Yellow Warblers. Auk 116:236-240.

9. McMaster D.G., D.L. Neudorf, S.G. Sealy and T.E. PItcher. In press. A comparative analysis of laying times in passerine birds. Journal of Field Ornithology.

10. NEUDORF, D. L. and S. G. SEALY. 1994. Sunrise nest attentiveness in cowbird hosts. Condor 96:162169.

11. PEER, B. D. and S. G. SEALY. 1999. Laying time of the Bronzed Cowbird. Wilson Bulletin 111:137139.

12. SCOTT, D. M. 1991. The time of day of egg laying by the Brown-headed Cowbird and other icterines. Canadian Journal of Zoology 69:2093-2099.

13. SEALY, S. G. 1992. Removal of Yellow Warbler eggs in association with cowbird parasitism. Condor $94: 40-54$.

14. SEALY, S. G., D. L. NEUDORF and D. P. HILL. 1995. Rapid laying by Brown-headed Cowbirds Molothrus ater and other parasitic birds. Ibis 137:7684.

15. SEALY, S. G., D. G. McMASTER, S. A. Gill and D. L. NEUDORF. 2000. Yellow Warbler nest attentiveness before sunrise: antiparasite strategy or onset of incubation? In: J. N. M. Smith, T. L. Cook, S. I. Rothstein, S. K. Robinson and S. G. Sealy (eds.). Ecology and Management of Cowbirds and their Hosts. University of Texas Press, Austin, Texas. p. 169-177.

16. TEWKSBURY, J. J., T. E. MARTIN, S. J. HEIJL, M. J. KUEHN, and J. W. JENKINS. 2001. Parental care of a cowbird host: caught between the costs of eggremoval and nest predation. Proceedings of the Royal Society of London, Series B 269:423-429.

17. WILEY. R. H. and M. S. WILEY. 1980. Spacing and timing in the nesting ecology of a tropical blackbird: comparison of populations in different environments. Ecological Monographs 50:153-178.

"Over the snowy drifts of the saskatoon flew mountain bluebirds, with backs and wings of glittering sapphire and breasts a softer blue." 